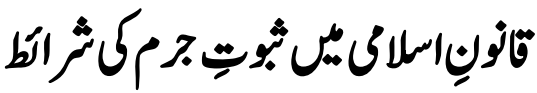

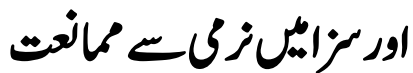

\section{Conditions of Proving a Crime under Islamic Law and the Prohibition of Leniency in Particular Crimes}

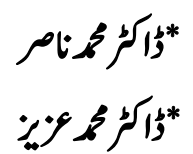

\begin{abstract}
Human Life has been granted great sanctity in Islam. In order to protect human life against any form of aggression, two types of punishments have been prescribed by Islamic Law; "hadd", which is a fixed and unchangeable form of punishment prescribed in certain cases, and "ta'zeer" which is the variable and discretionary part of punishment prescribed for cases other than "hadd". A deep analysis of these two types of punishments reveal that Islam wants to protect the life, honor and property of every individual because any violation against these three will result $\mathrm{n}$ disturbing the peace of the society which will lead to chaos and loss of trust among the society members. Since a society is seldom free form crimes, Islam does not want the individuals to take action against any type of crime because this will lead to arbitrary application of law which is against the very raison d'étre of any legal system. In this article, we analyze the conditions of proving a crime under Islamic law and we also shed light on the Prohibition of leniency in applying particular types of punishments.
\end{abstract}

Key Words:Crime,Sanctity, Punishment 'Hadd', 'Tazeer, arbitrary

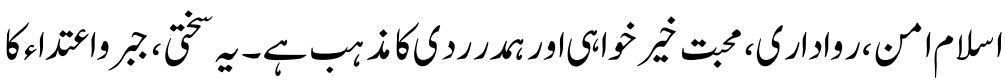

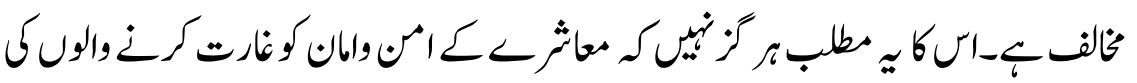

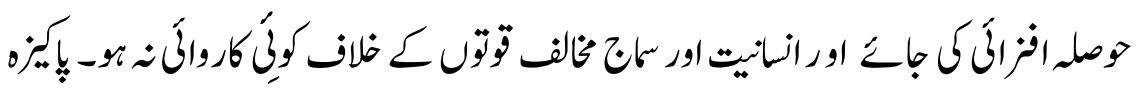

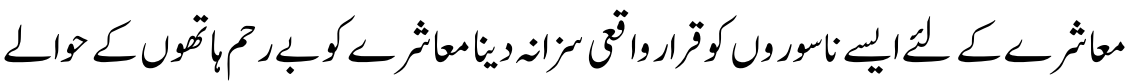

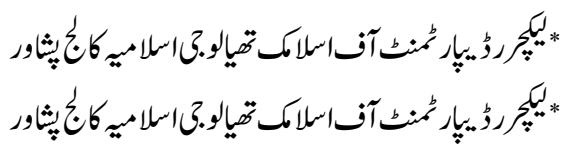




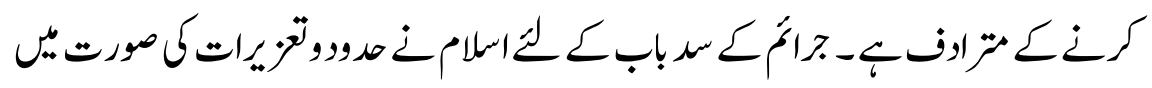

$$
\text { بزاوكاتصورياك- }
$$

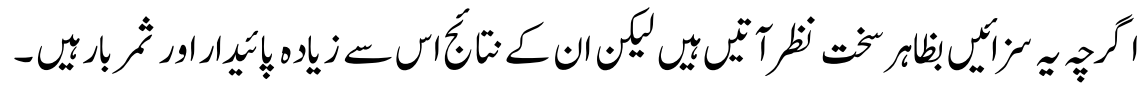

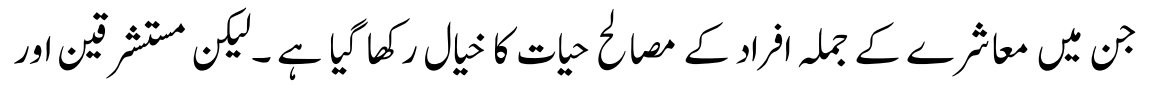

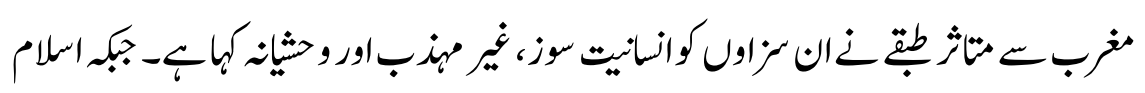

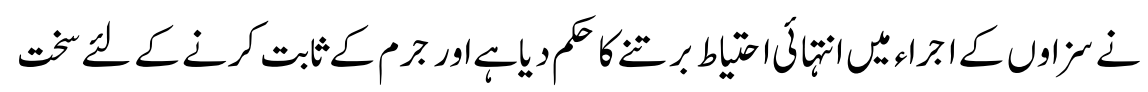

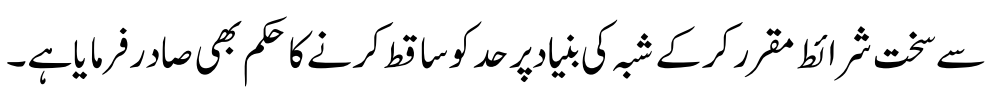

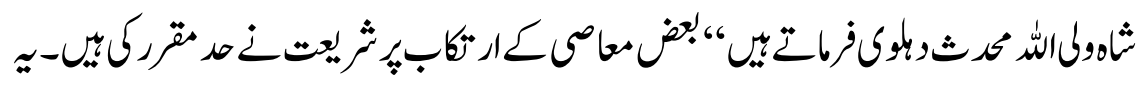

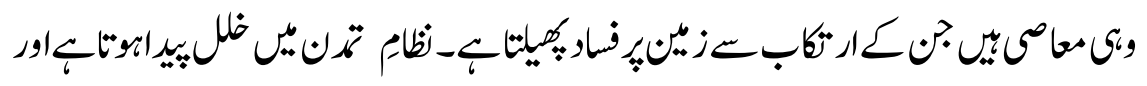

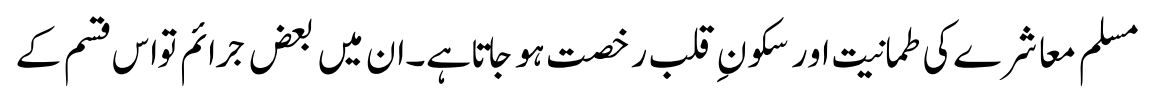

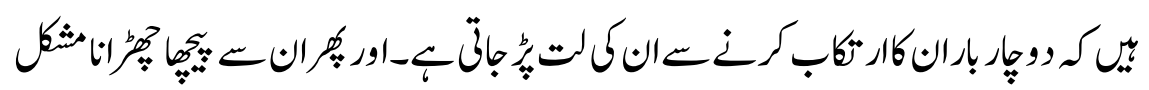

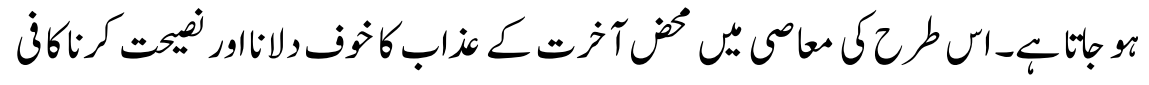

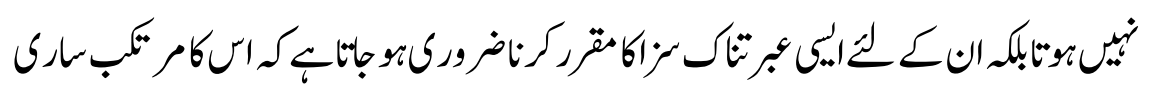

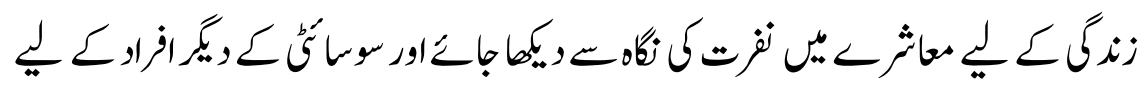

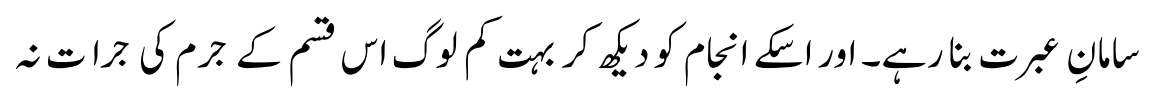

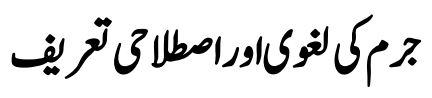

لنوى متن

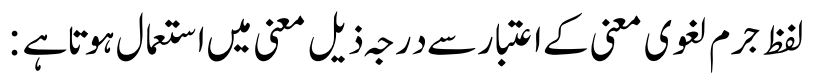

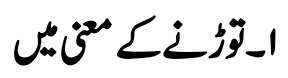

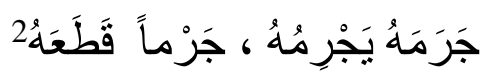

r 


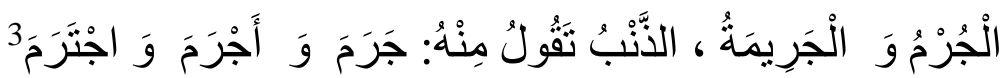

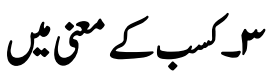

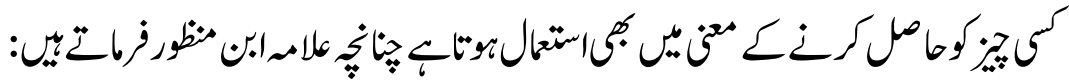

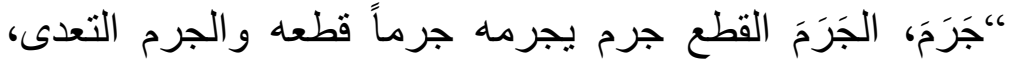

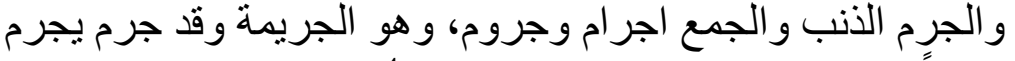

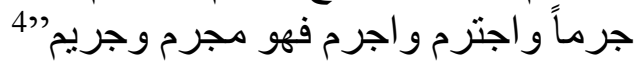

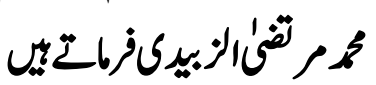

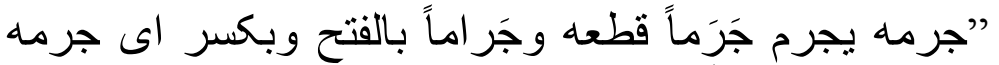

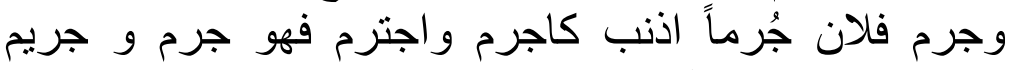

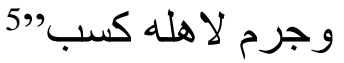

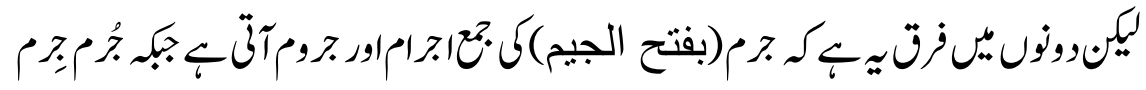

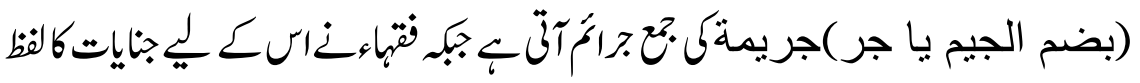
استحالكياب

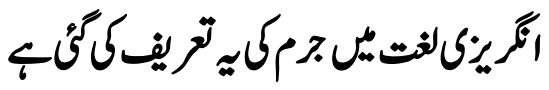

"A violation of a law in which there is injury to the public or a member of the public and a term in jail or prison, and/or a fineas possible penalties. There is some sentiment for excluding from the "crime" category crimes without victims,suchasconsensual acts, or violations in which only the perpetrator is hurt or involved such as personal use of illegal drugs. ${ }^{, 6}$

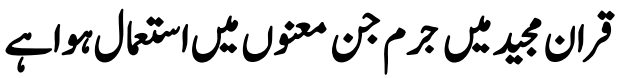

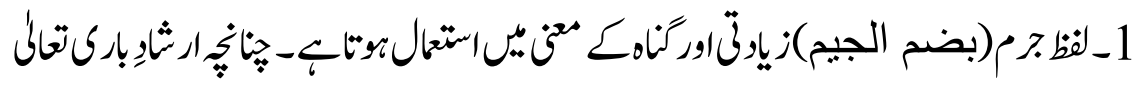

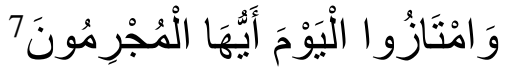

\section{$\div$}

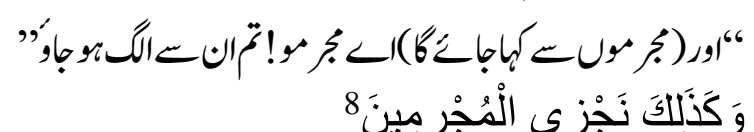

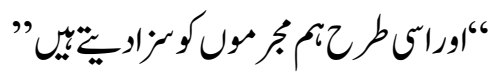

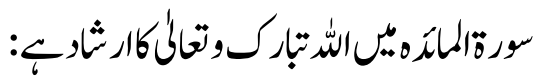




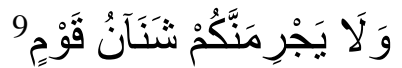

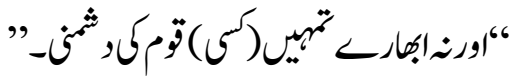

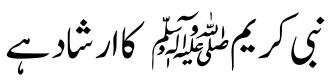

اجل مسالتهُ" المسلمين جرماً من سال عن شى لم يحرم فحرم من

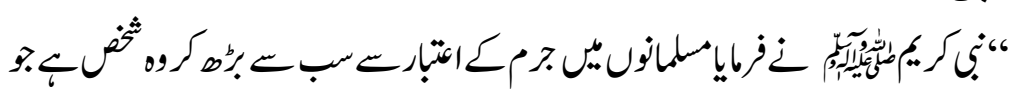

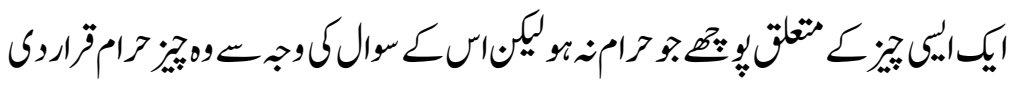

$$
\text { ج }
$$

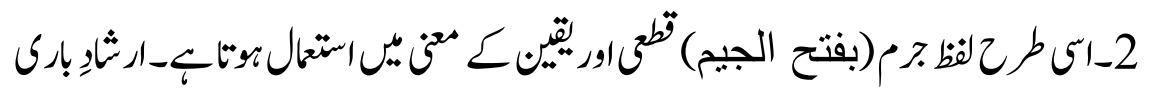

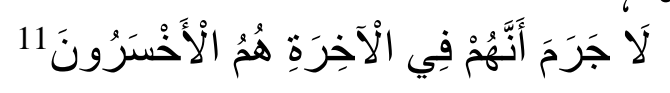
تحالظ؛

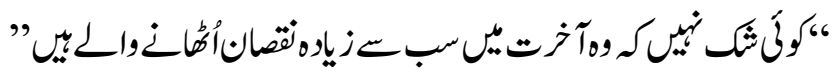

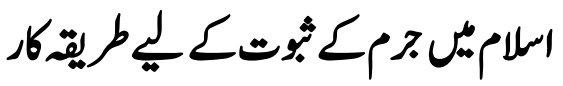

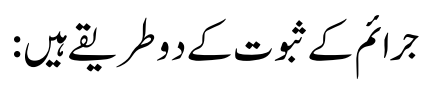

$$
\begin{aligned}
& \text { ل اترار }
\end{aligned}
$$

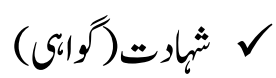

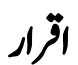

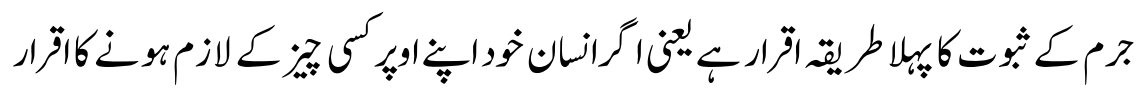

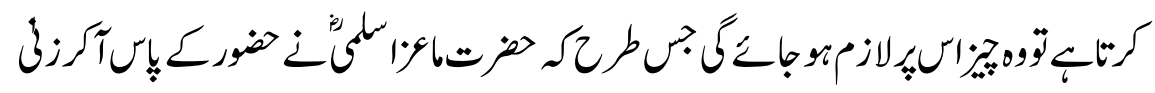

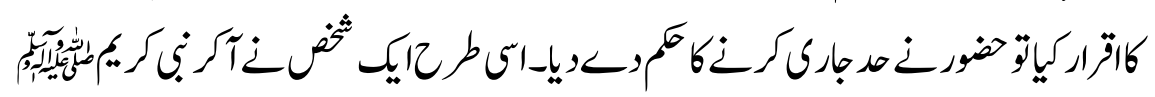

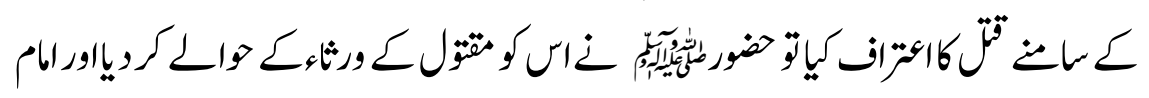

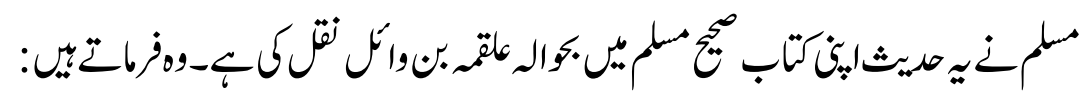

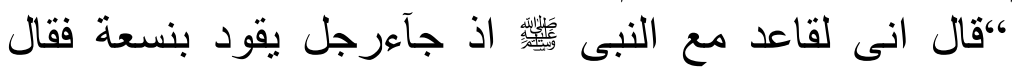

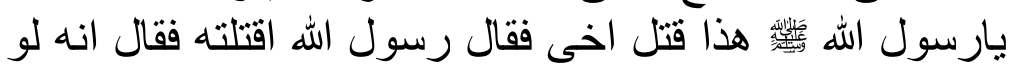
لم يعترف اقمت عليه البينة قال نعم قتلتهـ"12 


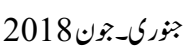

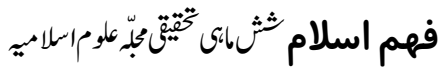

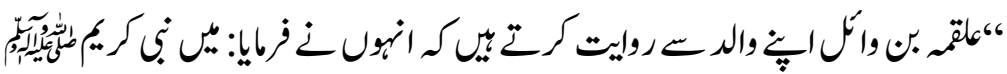

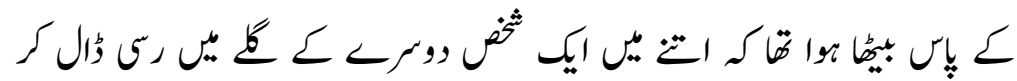

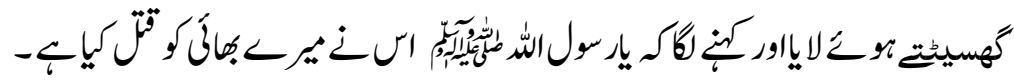

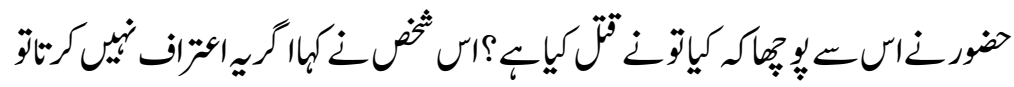

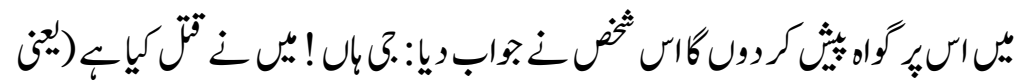
اوتزافكيا)"

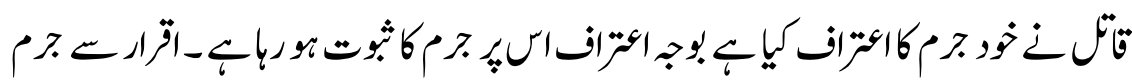

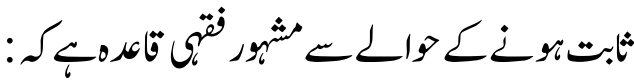

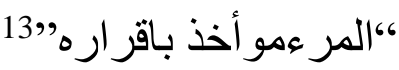

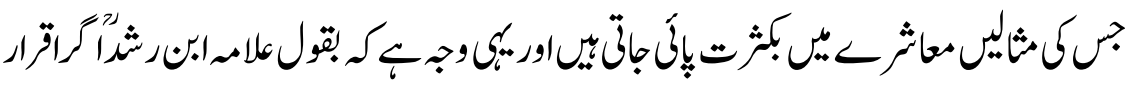

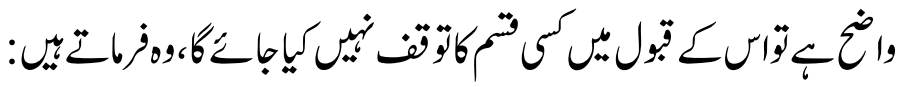

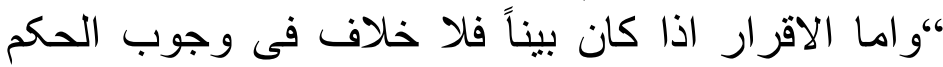

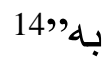

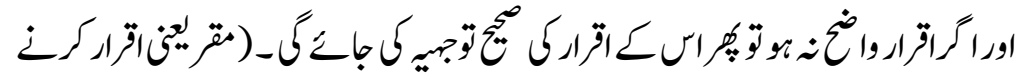

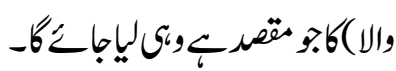

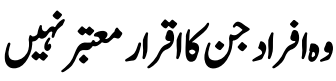

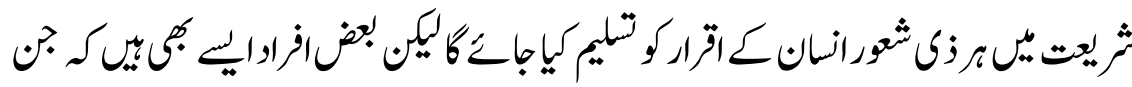

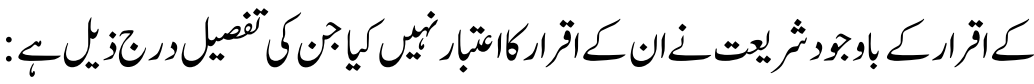
1. به:

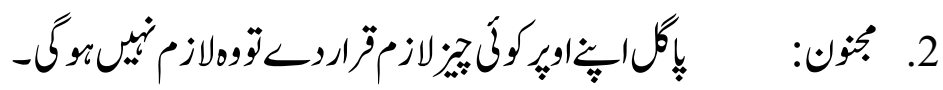

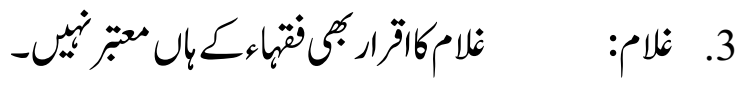

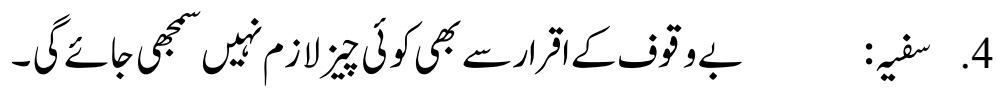

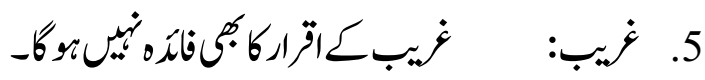

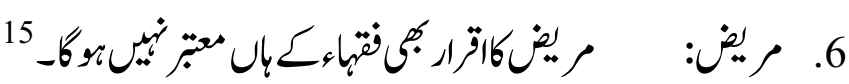

27 


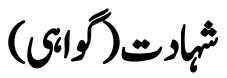

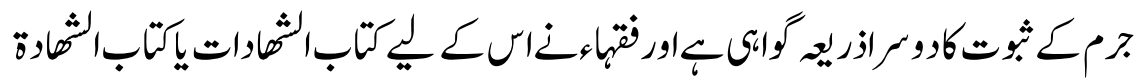

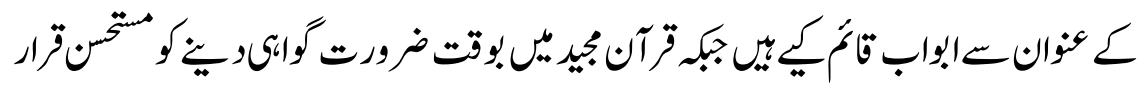

بإ-

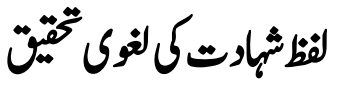

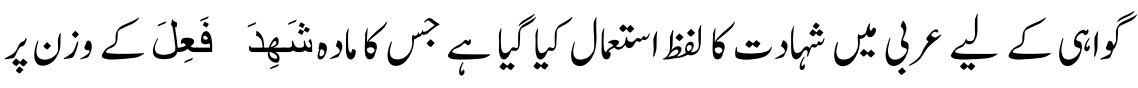

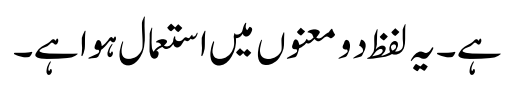

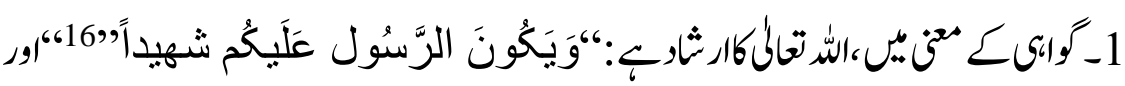

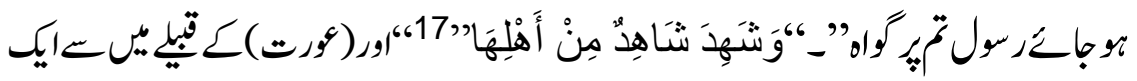

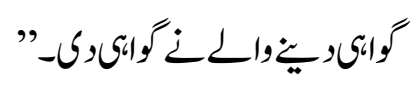

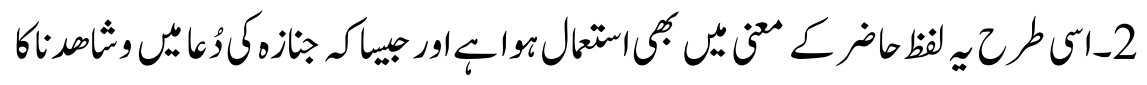

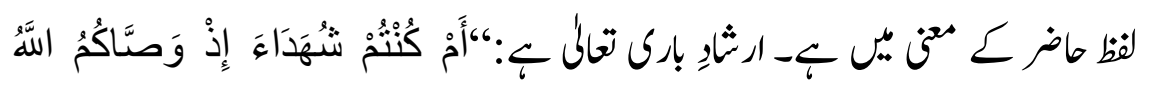

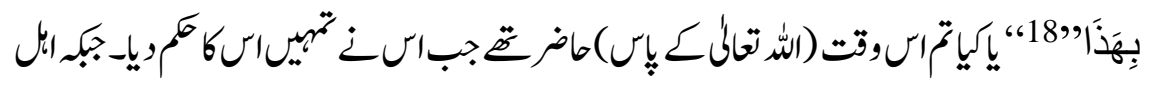

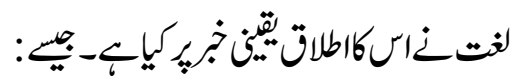

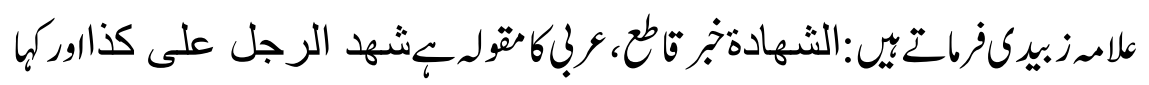

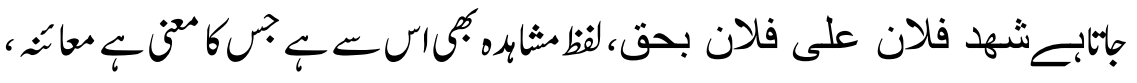

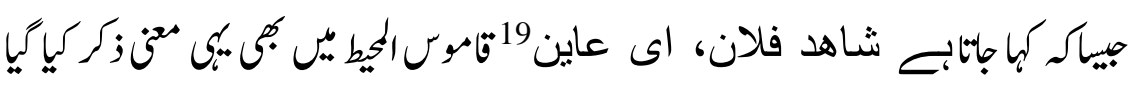
ب:“"الثهادة خبرقاطع. وشاهدهعانيه”"

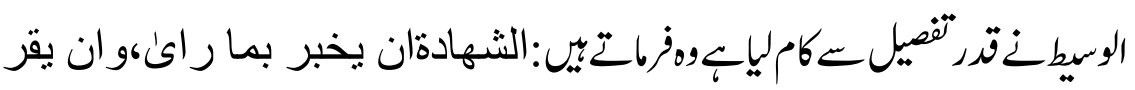

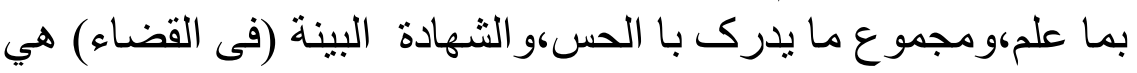
اقو ال الثهود امام جهة قضائية" 21

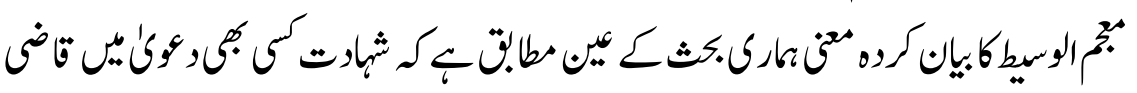

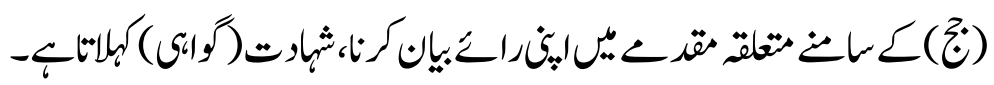




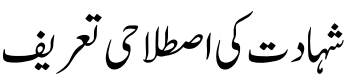

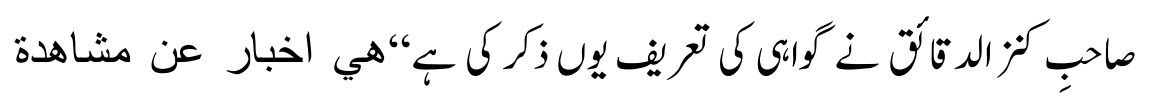

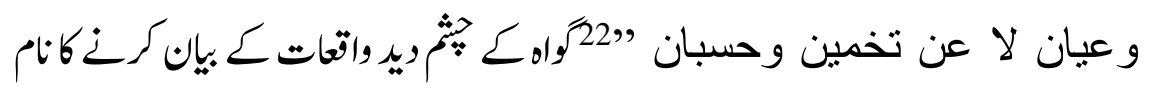

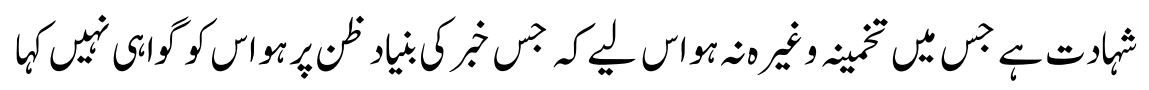
ج

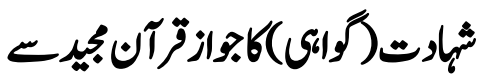

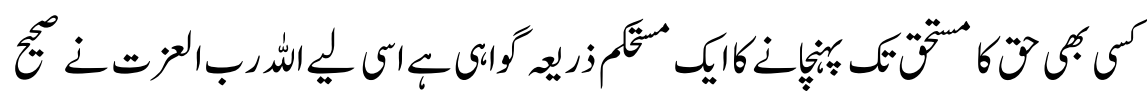

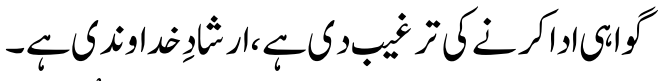

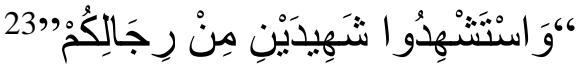

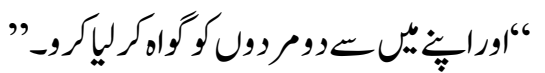

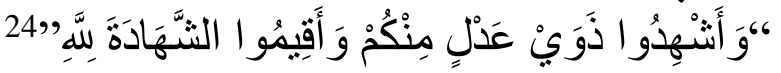

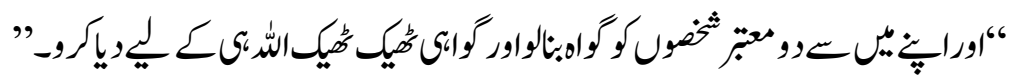

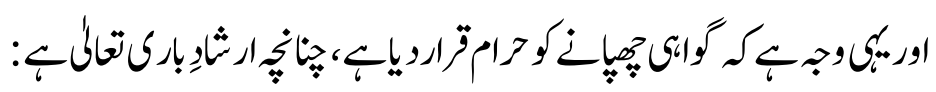

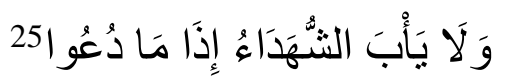

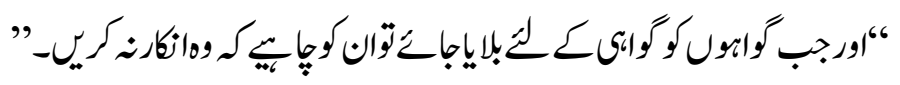

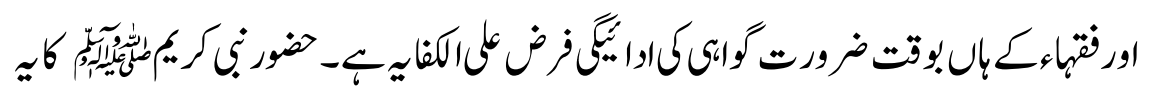

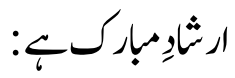

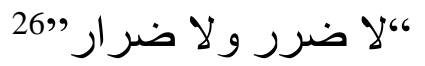

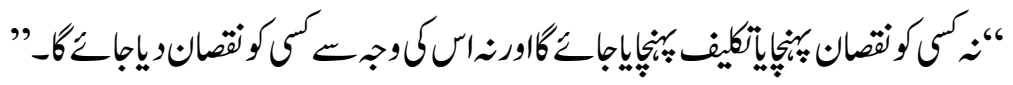

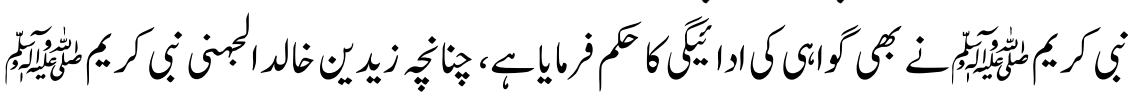

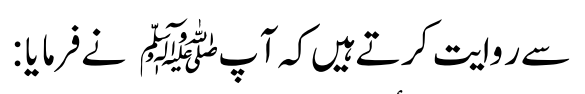

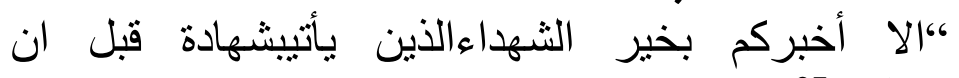




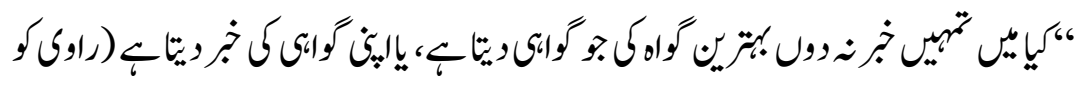

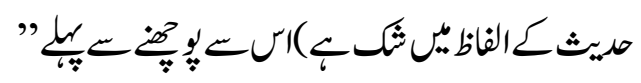

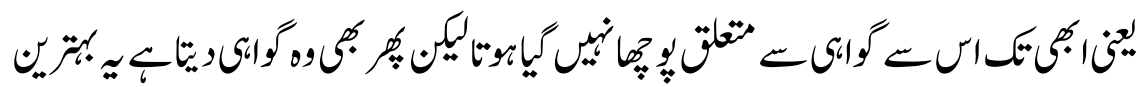

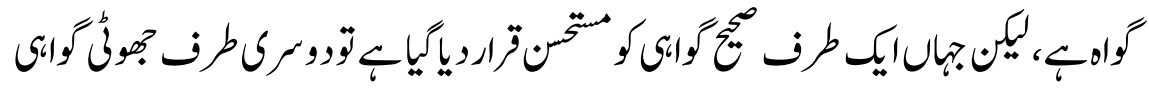

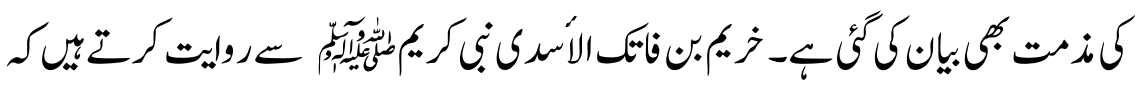

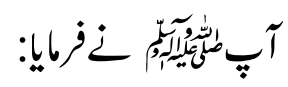

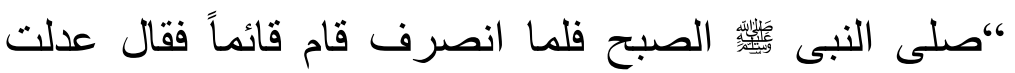
شهادةالزوربالثركباللهثيلاثمرات

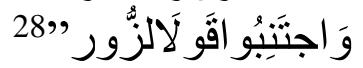

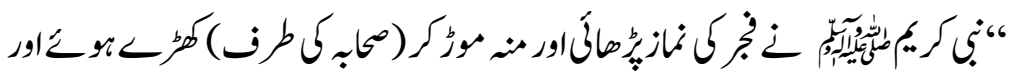

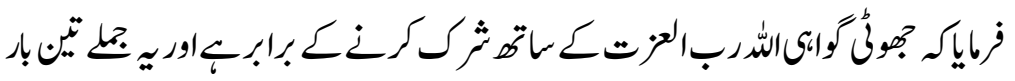

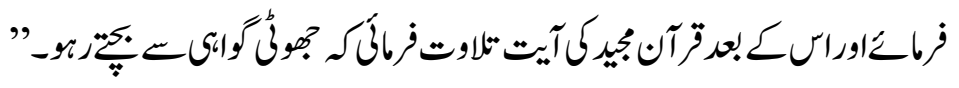

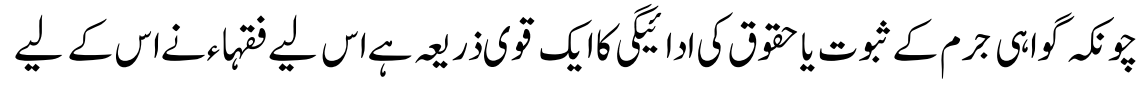

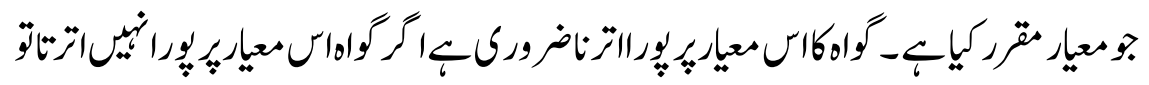

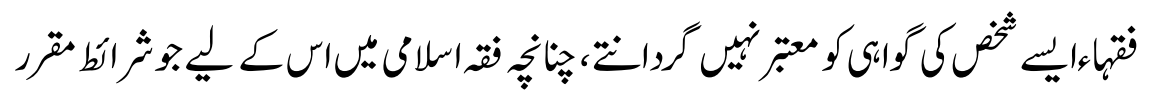

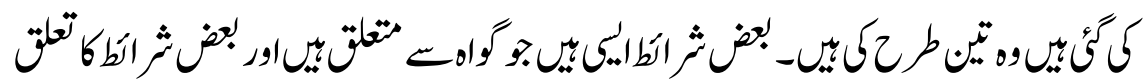

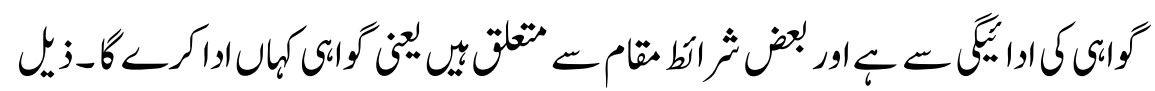

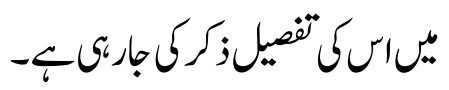

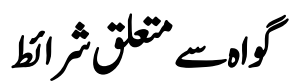

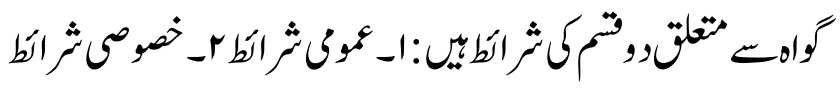

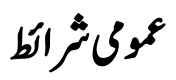

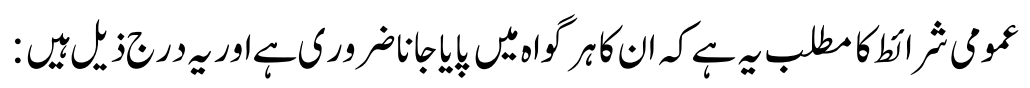




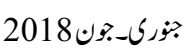

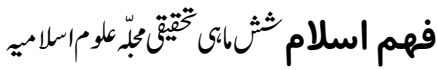

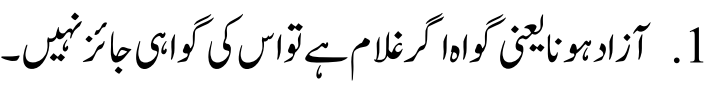

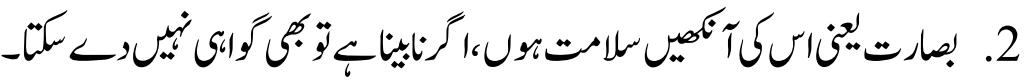

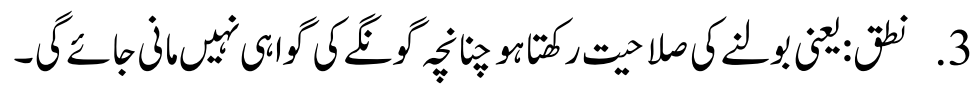

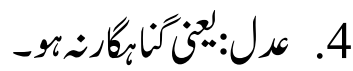

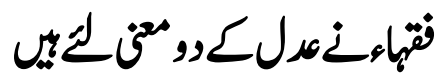

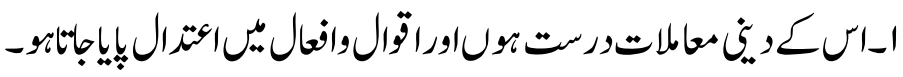

"، "و هياستو اءاحو الهفيدينهو اعتدالاقو الهو افعاله"

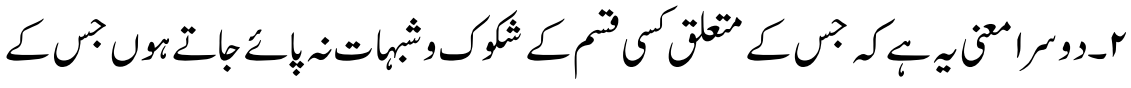

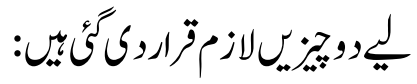

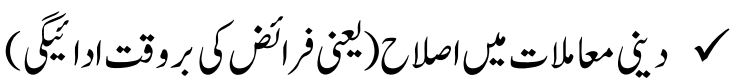

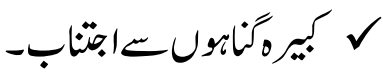

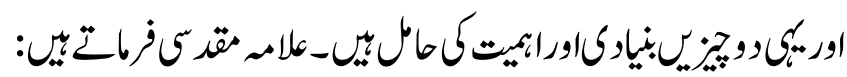

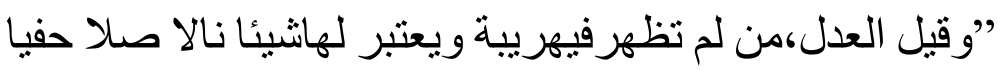

لديناو هو اداء الفر ائضو اجتنابالمحار مو هو انلاير تكبكبيرة لائو لايدين

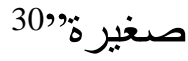

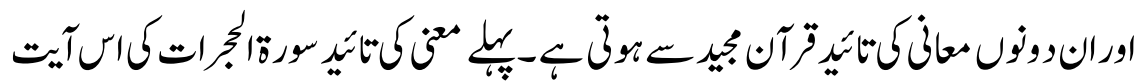

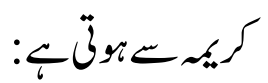

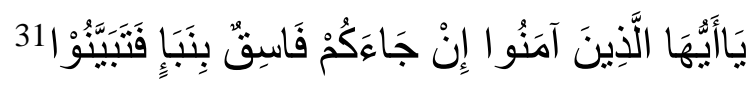

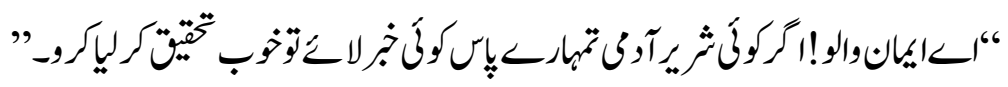

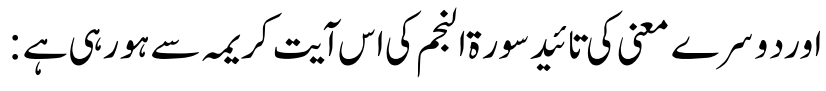

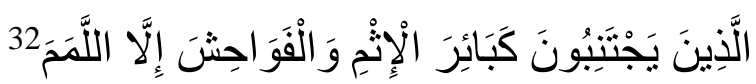

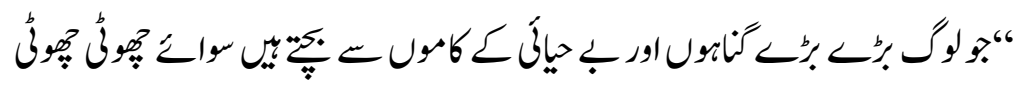

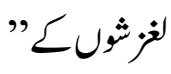

31 


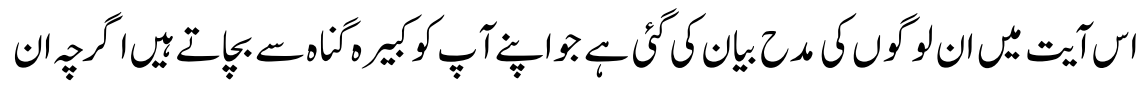

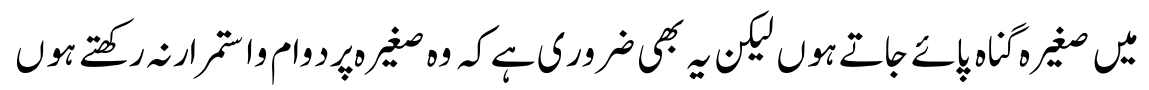

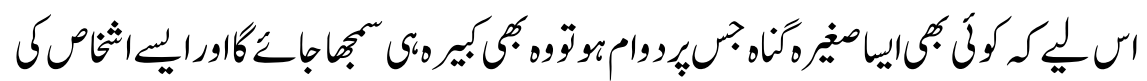

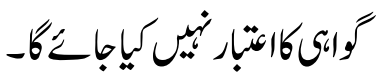

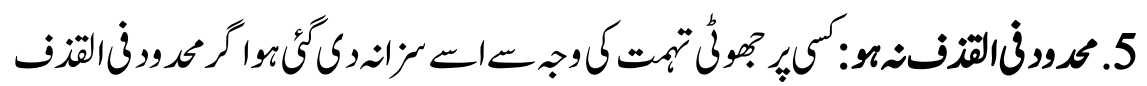

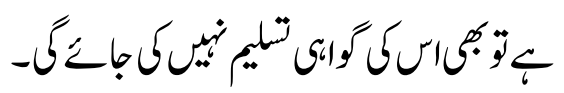

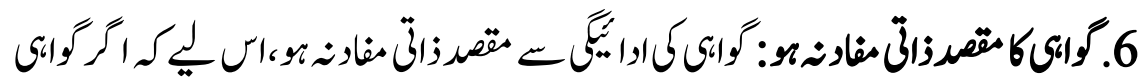

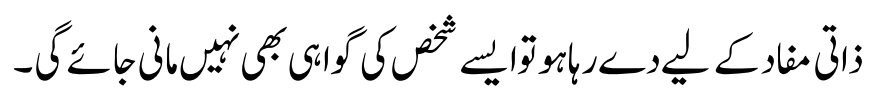

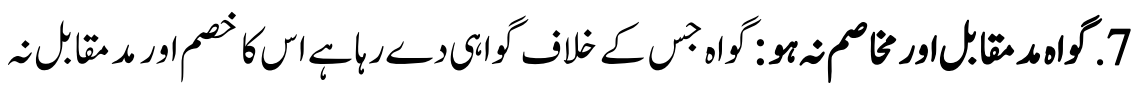

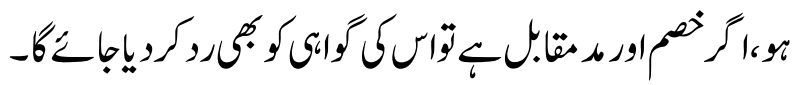

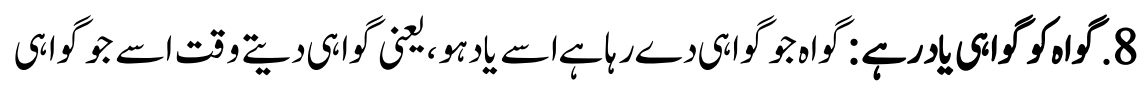

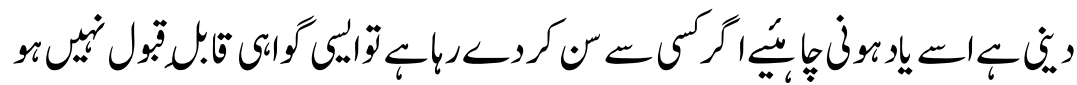

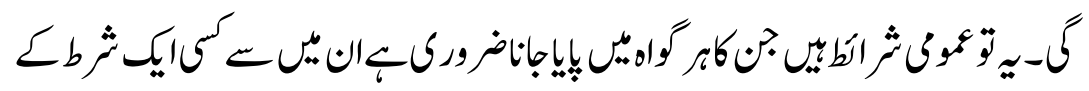

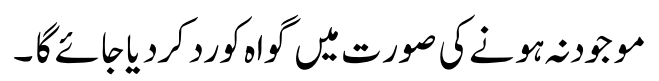

\section{خصوصنثمائط}

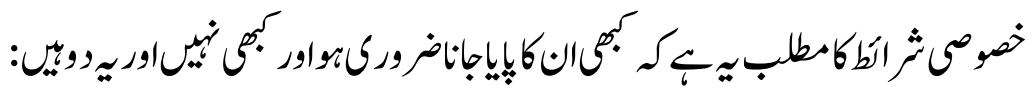

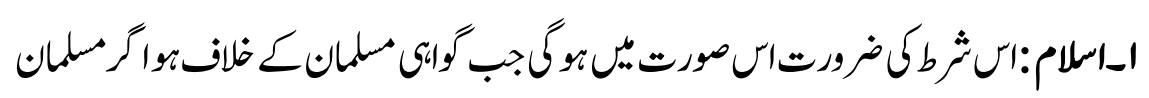

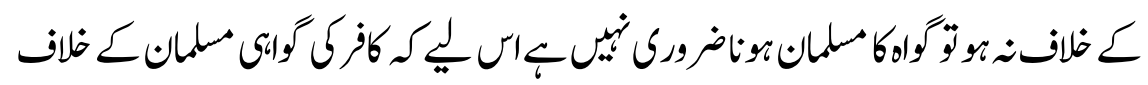

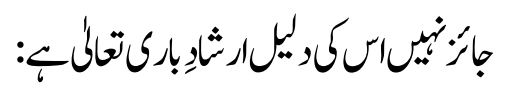

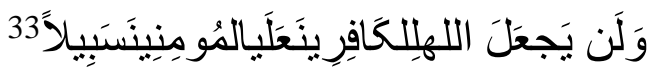




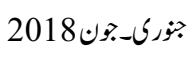

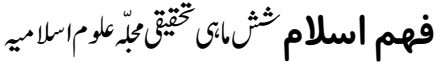

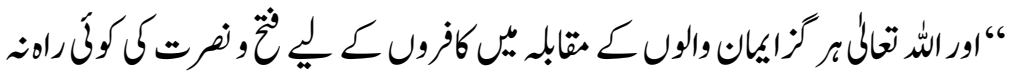

كو

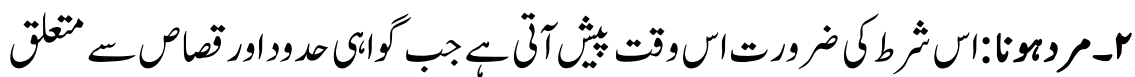

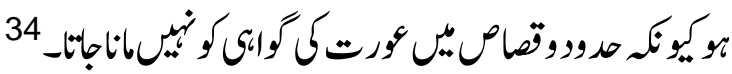

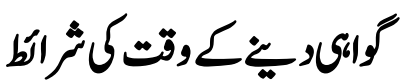

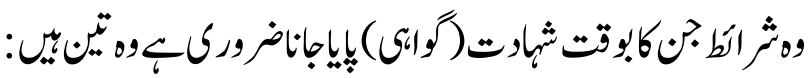

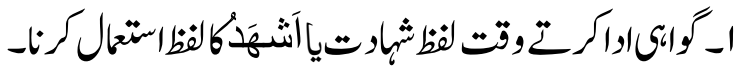

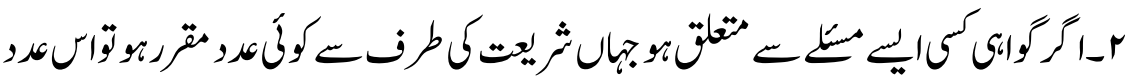

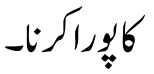

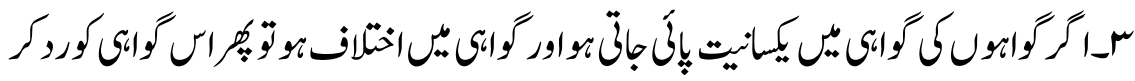

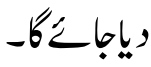

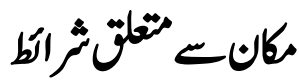

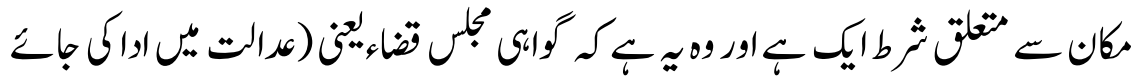

$-6$

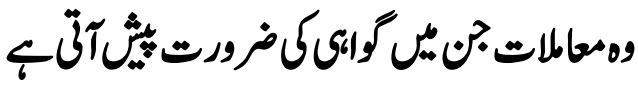

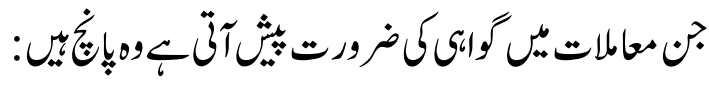

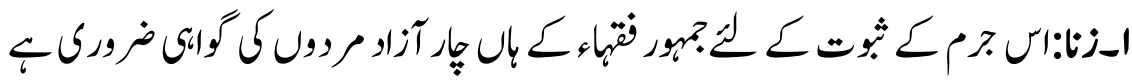

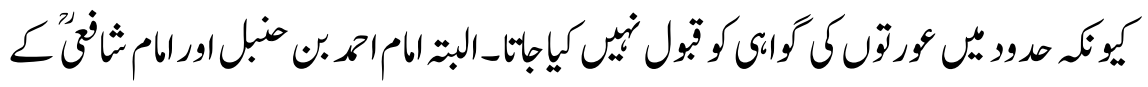

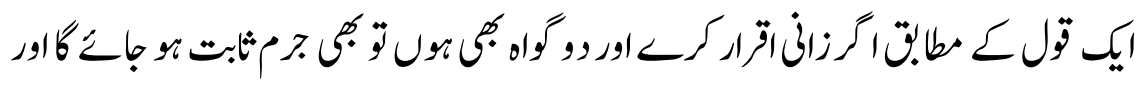

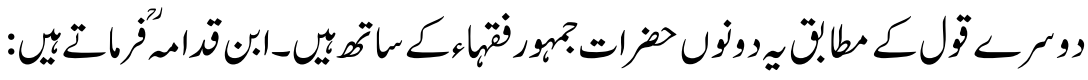

و هليثبت الاقرار احدهمالا يثبت الا باربعة وهو المذهب و وعليه

الاصحاب لانه وجب لحد الزنا فاثبه فعله والثانية، يثبت

33 
بشاهدين قياساً على سائر الاقارير وللشافعيرحمه الله قو لان

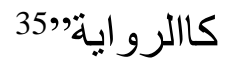

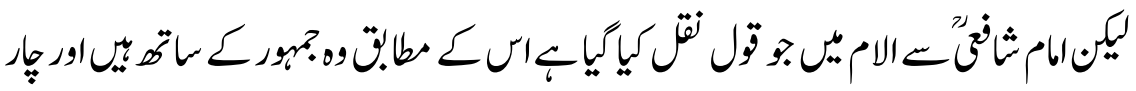

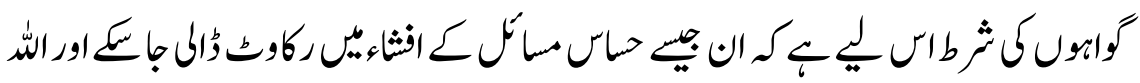

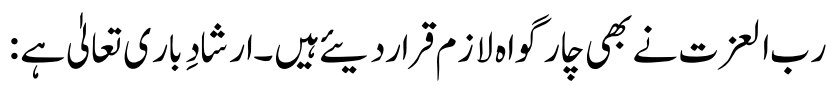

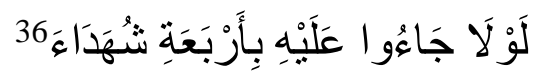

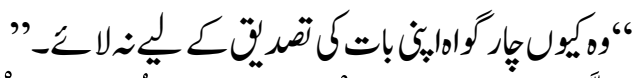

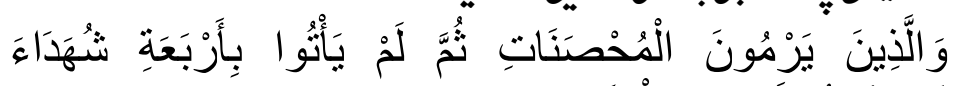

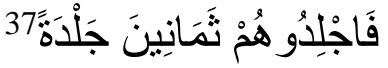

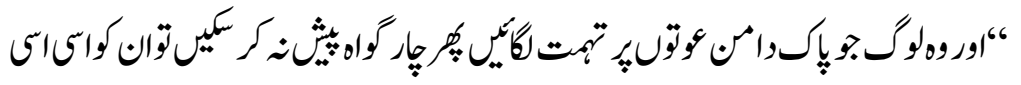

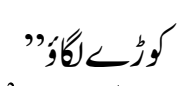

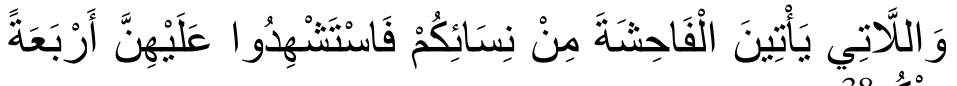
مِنْكُمْ 38

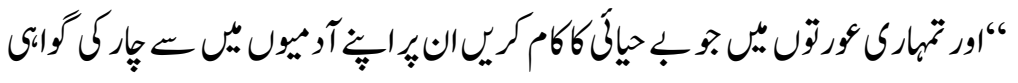
لو

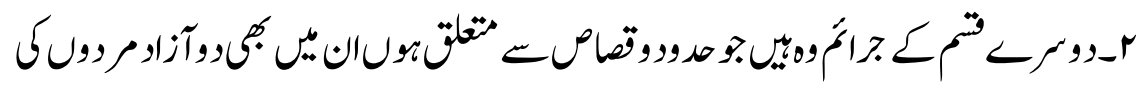

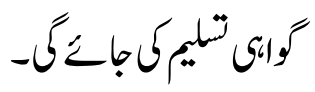

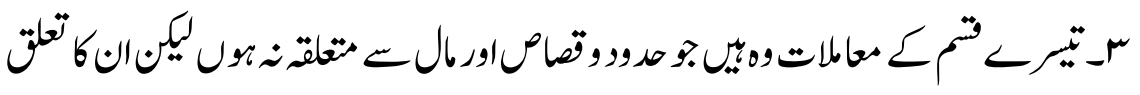

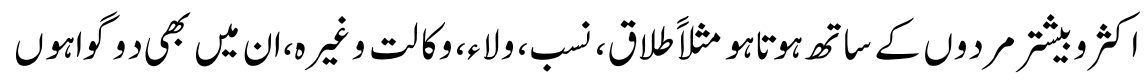

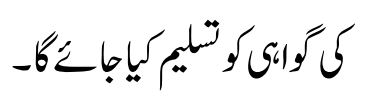

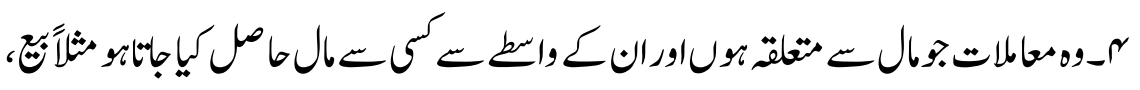

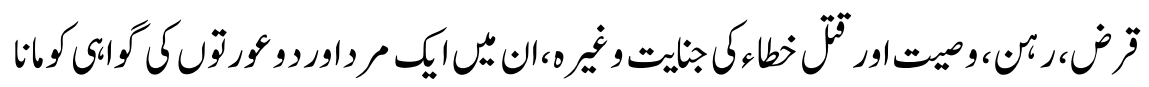

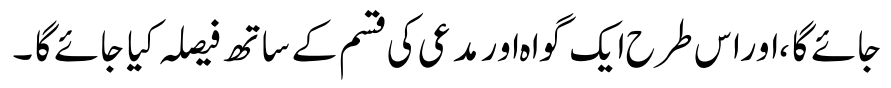




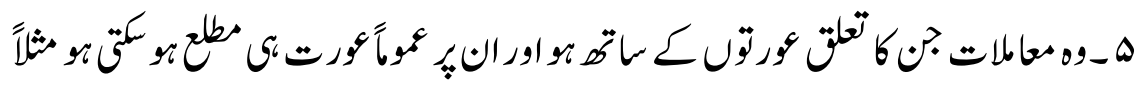

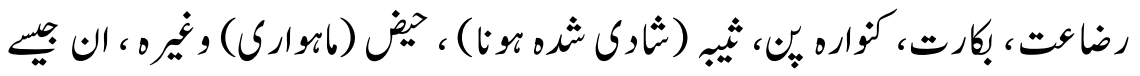

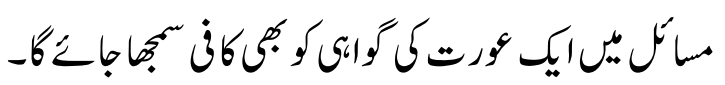

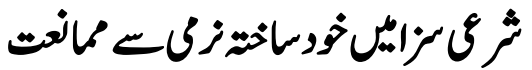

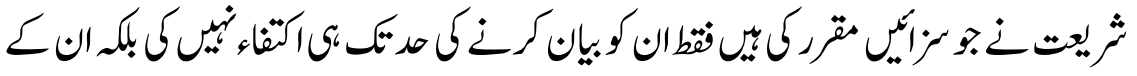

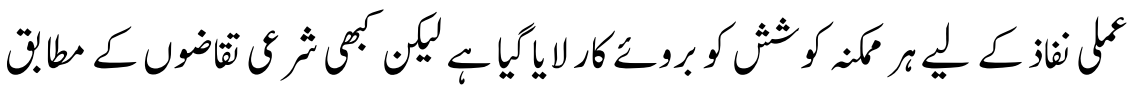

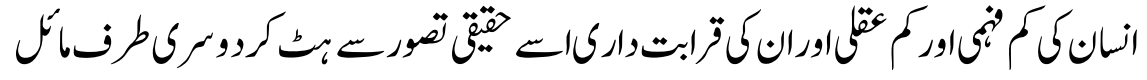

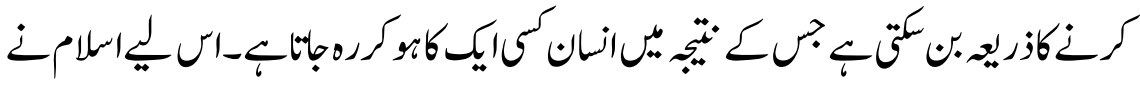

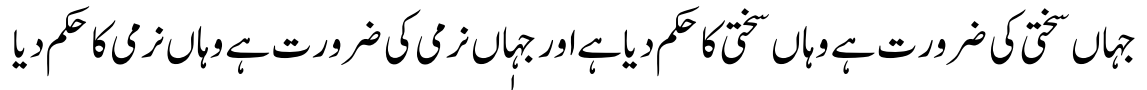

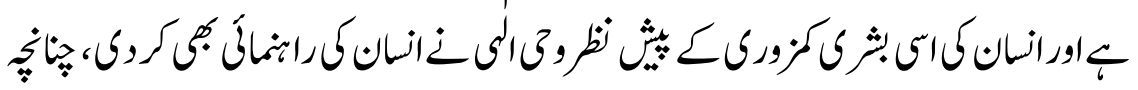

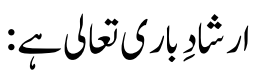

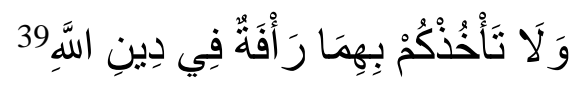

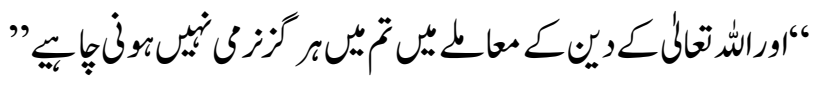

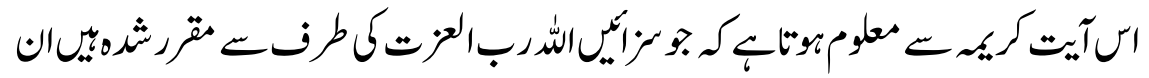

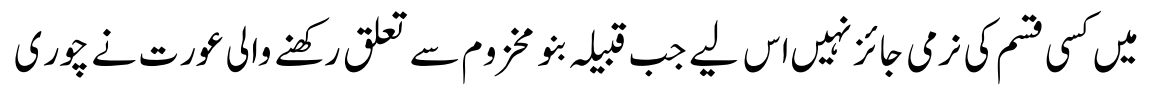

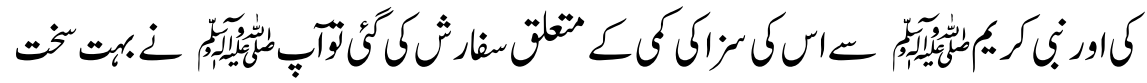

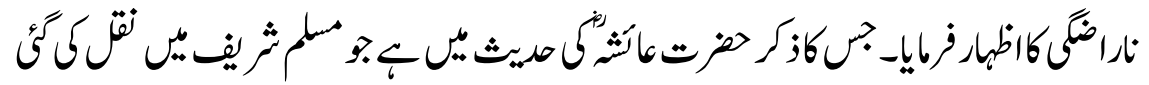

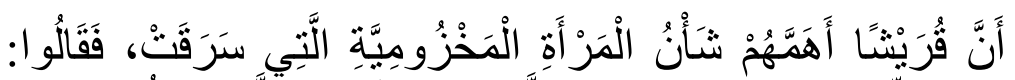

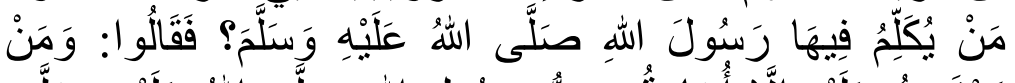

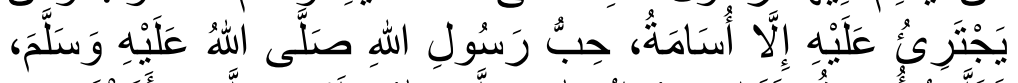

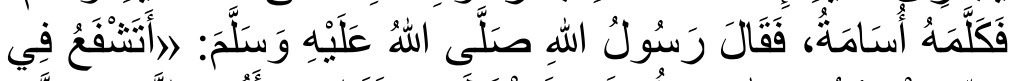

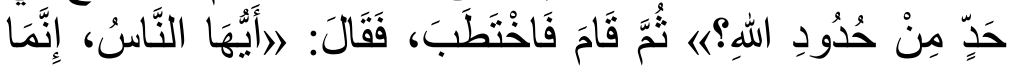




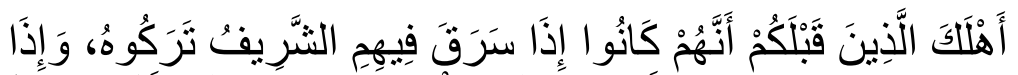

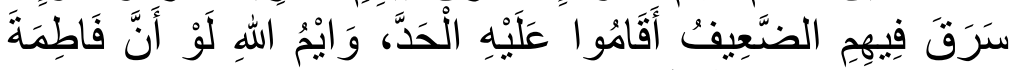

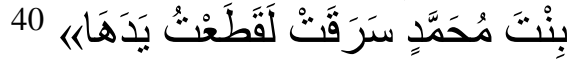

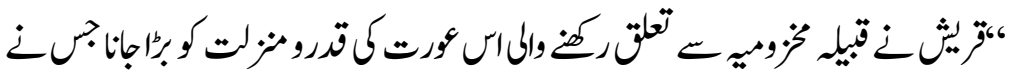

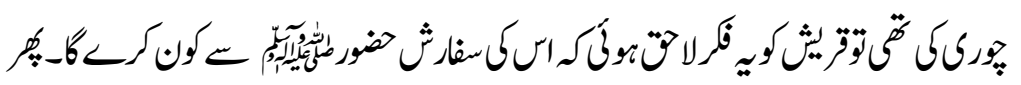

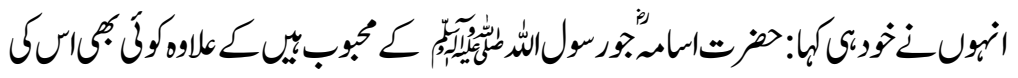

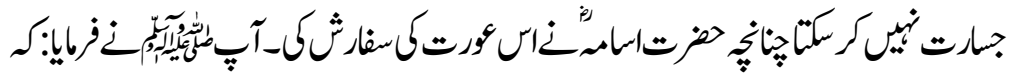

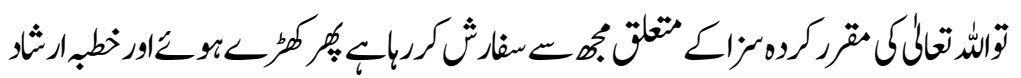

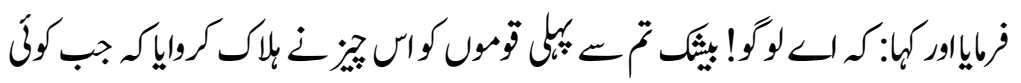

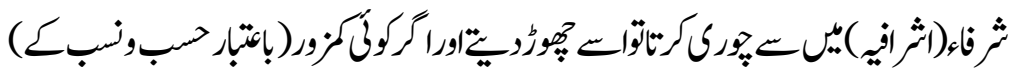

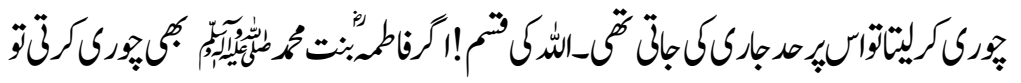

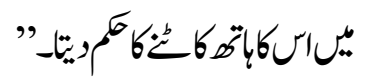

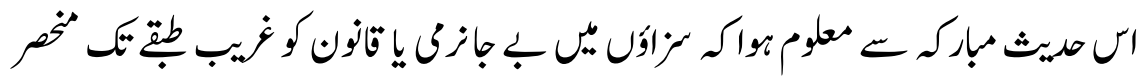

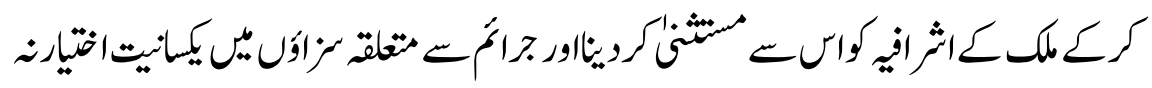

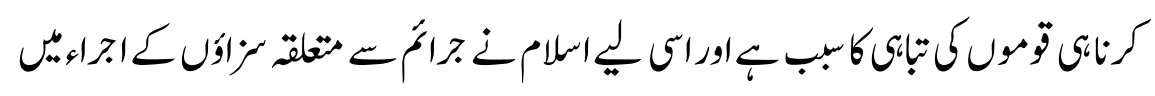
كثن

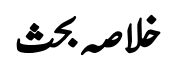

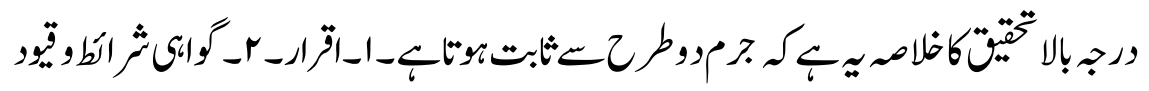

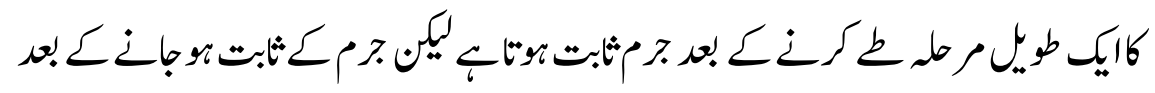

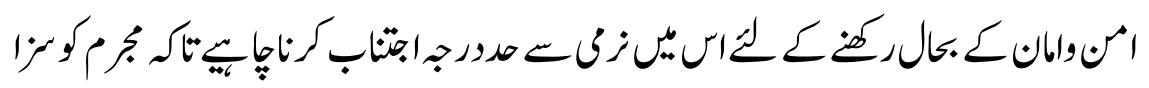

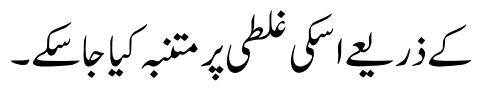




\section{واثىوهوالهجات}

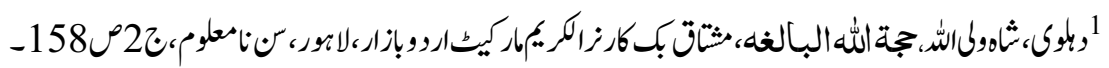

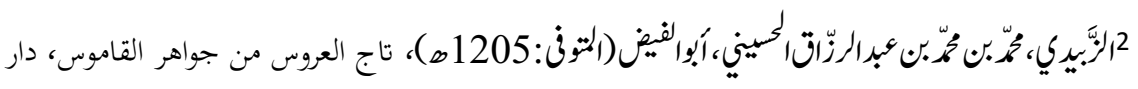

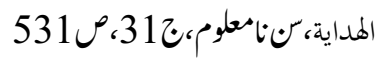

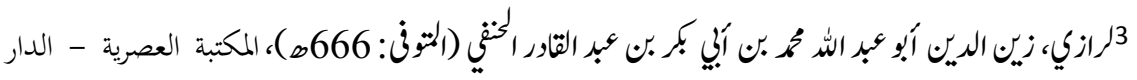

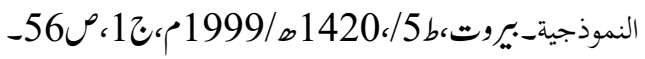
4ابن منظور،حممد بن مكرم بن على، أبو الفضل، جمال الدين (المتوف: 711هـ)لسان العرب،دار صادر -

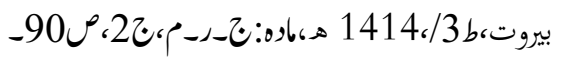

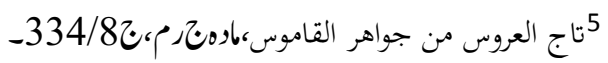

${ }^{6}$ William Collins sons,Collins English Dictionary,Harpercollins Publishers,2012.

$$
\begin{aligned}
& \text { 7الق آنا،بورةتئين :59- } \\
& \text { 8ن نمصدر،الا كواف:40- }
\end{aligned}
$$

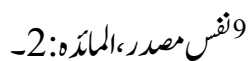

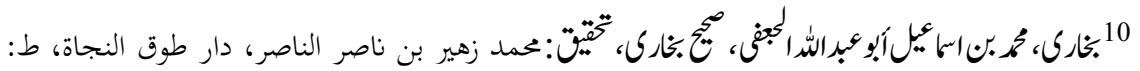

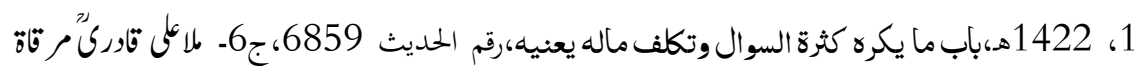

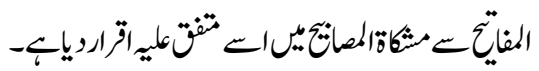

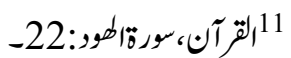

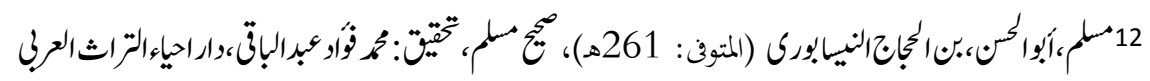

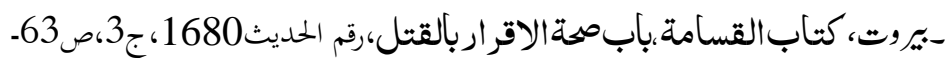

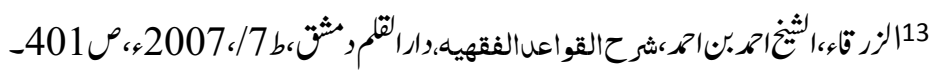

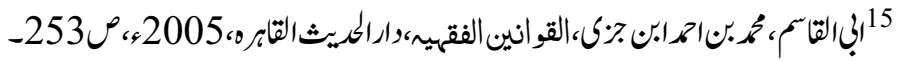

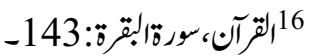

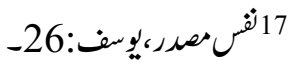

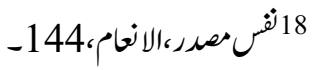




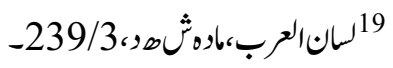

20:

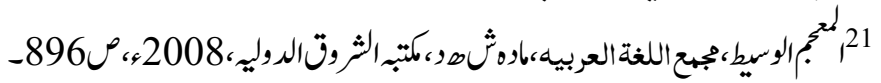

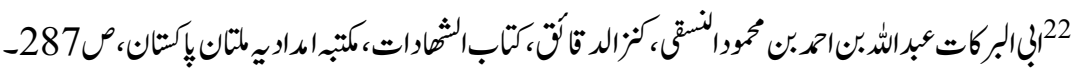

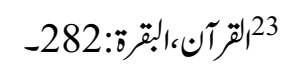

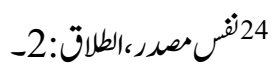

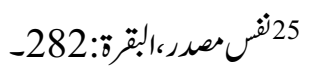

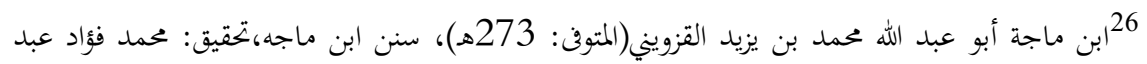

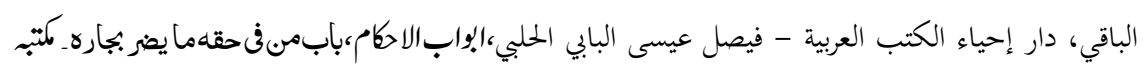

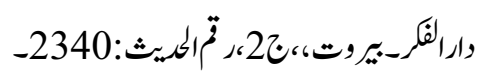

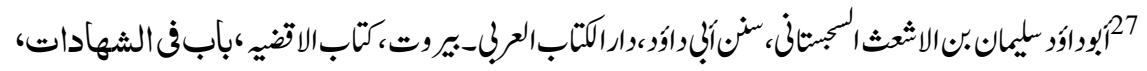

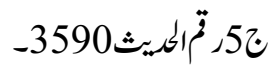

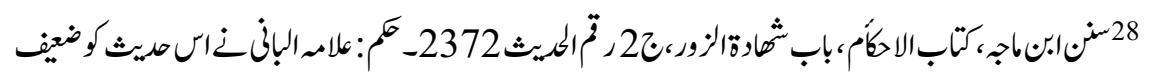

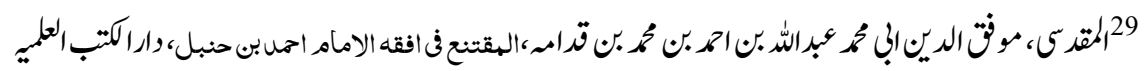

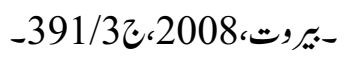
391-392، 30

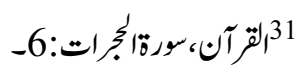
23:-23: 32 333 33

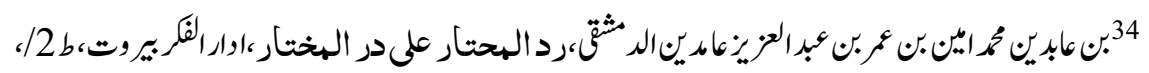
462/5『، 1992

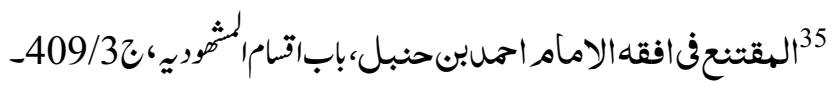

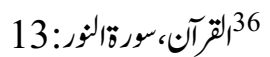

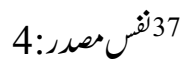
15:38 38

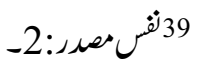


40هلم، أبو الكّ،بثن المجاج النيالورى (المتوف: 261هـ)، صيح سلم، باب قطع السارق الثريف وغيره

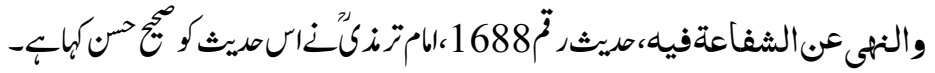

